\title{
Agreste: uma dramaturgia desejante
}

\author{
Antônio Rogério Toscano
}

greste (2001), de Newton Moreno, é uma dramaturgia-desejo. Costura dolorosa, em que forma e tema se entrelaçam e se rasgam continuamente, às vezes para bordar um mesmo fio narrativo, em outras para dar ressonância ao grito híbrido daquele que vive na margem do que é aceitável para o mundo, a obra permanece em perpétuo movimento e não se acomoda à convenção. Faz isso para se aproximar, com seu formato aparentemente simplório (mas muito sofisticado) e com sua delicadeza provocadora, da fábula tímida cujo recheio é o homoerotismo.

Inquieta, a peça possui tensōes internas, construídas com dinamismo dramatúrgico, que não se resolvem na superfície de um primeiro olhar. O que aparenta pertencer a determinado gênero, de fato esconde facetas ambíguas, e, nas camadas profundas, um gênero pode degenerar em outro, em assumido recorte como "transgênero" e contemporâneo.

Em síntese, Agreste é formalmente um travesti cujo corpo estrutural é transitivo, de gênero móvel, tanto quanto o é a figura de Etevaldo, presença cênica de um nordestino mítico, apenas narrado e inexistente como matéria concreta.

Se, na aparência, a peça trata do drama romântico de um casal sertanejo que, depois de desconfiada aproximação, corre por um longo e ressecado estradão de terra árida - que leva ao sertão mais fundo do Brasil - para proteger a fragilidade de seu amor, numa segunda etapa de camadas mais profundas, reveladoras do desejo -, o recorte narrativo se concentra em escavar segredos e em flagrar o casamento lésbico de duas mulheres de vidas secas que guardam escondido, inclusive para si mesmas, um amor que não pode ser nomeado.

Na fábula: a ambigüidade, evidenciada pela reviravolta.

Mas, ao migrar o foco do tema (homoerotismo) para levá-lo de volta à formalização da dramaturgia, o que se nota é que nada do que se narra pertence, de fato, à diegese dramática da cena: não há drama, senão aquele relembrado pela textura narrativa. $\mathrm{Na}$ concretude da cena, um mediador conduz até o público o que só pode ser imaginado, na consagração do rito teatral.

No ápice da narrativa, o velho contador de histórias tenta tornar visível o que é imaterial, pura imagem abstrata:

"Se pudesse falaria no ouvido de Deus. Cantou sua fé com devoção sincera, o que dá no mesmo. Olhe, música e Deus ninguém vê.

Antônio Rogério Toscano é dramaturgo e pesquisador, mestre pelo Instituto de Artes da Unicamp. 
Fé ninguém toca, nem se mede. Mas juro: acontecia livre cada centímetro de Jesus, na voz dela.”

O invisível - e, portanto, sagrado (Brook, 1970) - é o que eleva a cena para a dimensão do rito. O texto projeta, com seu desejo intrínseco, a chegada do (outro) artista cênico que encontrará a medida de sua encenação. Assim é o que a dramaturgia de Newton Moreno pede, ou exige: um defloramento que corrompa sua forma original. Eroticamente, coloca-se em jogo o desejo da transitividade, do devir criativo.

Não há padrões anteriores que garantam, para a dramaturgia contemporânea, uma forma teatral exata. Se ela é, sobretudo, pulsão não há porque se temer invadi-la. Se ela chama para o jogo, só resta ao artista do palco jogar com suas arestas, com suas lacunas e com suas incorreções premeditadas.

Disforme, Agreste não se enquadra aos padrōes convencionais da dramaturgia tradicional. Transitiva, projeta sobre si a intervenção e a necessidade de diálogo criativo com a alteridade - tanto de outros artistas como também do espectador.

Dona de textualidade, portanto aberta, a peça deseja a re-semantização elaborada pelo outro, que a complete. Escapa dos territórios mapeados e vai buscar o belo em um limite do palco, que é a fronteira entre a simples narrativa e a abstração cênica.
Lá, onde dramaturgo, encenador, atorcriador e público (além dos demais criadores por ventura envolvidos no projeto) se reúnem para cravar no espaço e no tempo a sua escritura espetacular. Lá, onde os procedimentos colaborativos modificam o próprio conceito de dramaturgia. Mais longe ainda, lá, onde a relação entre texto e cena está por ser (re-) inventada, é que está a morada do trabalho de Newton Moreno como dramaturgo contemporâneo.

Assim, Agreste nasceu como uma narrativa dramática. Mas cresceu e se transformou muito, de casulo a borboleta.

Mesmo como peça de forte tonalidade épica, continha, desde a origem, em seu formalismo depurado, elementos ambíguos: inquietos, desejantes, irredutíveis à classificação tradicional.

Pois estes elementos - carga lírica incomum, palavra de impacto sensorial, abstracionismo narrativo, imagens simbólicas incongruentes: "Ele desapareceu a ela" - não permitiam que se firmassem, como parte de sua ossatura dramatúrgica, os valores categóricos de uma narração teatral - ou, ao menos, daquilo a que se acostumou chamar de teatro narrativo: fragmentário, distanciado, político etc.

Ainda distante da cena ${ }^{1}$, em sua versão escrita, o bloco de texto agreste do autor recifense chegava ao leitor como uma ferida ambivalente: na sua própria linguagem, um pouco como cicatriz, outro tanto como flor. ${ }^{2}$

1 Antes de qualquer outro comentário, é preciso revelar ao leitor a situação privilegiada em que me encontro, ao observar o trabalho artístico de Newton Moreno.

Em diversas situações, desde as primeiras parcerias (na época de nossa formação, na Unicamp do início dos anos 90, quando dividimos uma república na moradia estudantil), estive próximo de sua criação. Depois, fosse como intérprete de um texto meu (em Sacromaquia, espetáculo dirigido por Maria Thaís em 2000), fosse como dramaturgo com quem dividi a pena, colaborativamente (em Santa Luzia passou por aqui com seu cavalinho comendo capim, sob direção de Georgette Fadel, em 2004), sua obra sempre ressoou em meus ouvidos, sobretudo, como algo próximo e familiar.

No caso específico de Agreste, coube justamente a mim a coordenação e a direção de sua primeira leitura pública, em 2002, para o projeto Devassos na dramaturgia, que inventamos e levamos juntos ao Festival de Teatro de Curitiba. Realizamos essa apresentação, sob a forma de mise-en-space, também em São Paulo e na Escola Livre de Teatro de Santo André (ELT), em 2003. 
Flor porque, como seu viu, seu desabrochar épico aproximava-a do campo ritual, como na tradicional cena oriental, quando pedia que narrativa, movimento, música, dança, poesia e outros fatores expressivos preenchessem o espaço vazio com o requinte de um gesto/pétala de um ator/sacerdote nô.

Cicatriz porque a beleza vazava do texto carregada de culpa. O desejo homoerótico travestido criava camadas de desconfiança entre as personagens, mas também entre leitor e texto: "Uma cerca os separava".

Em uma primeira leitura, o corpo - templo do rito erótico - tornava-se então reduto de doloridos desejos mascarados, amalgamados a perseguiçōes e ao medo. Houvesse um único toque físico entre os amantes - dramaturgo e leitor? - e tudo podia escorrer em mentira. Precisão milimétrica para afugentar o arriscado contato, ainda perigoso:

“Ele andava muito para encontrá-la. Mas quando se viam, ficavam, no mínimo, a cinco metros de distância. Nem um centímetro a mais ou a menos. Exatos cinco metros. Sempre. Uma cerca os separava."

Mistura inquietante entre culpa e liberdade - afinal, se a peça era desejante, o melhor a fazer seria penetrá-la com a fúria invasiva de quem quer pôr pingos nos is -, a força da palavra rasgava a pele em que se escrevia o amor:
"Ele deixava sangue no arame da cerca, Ela ia enxugá-lo”.

Desde a nascente, este rio "de areia e de sede", desenhado no vento pela correria e pela fuga dos amantes, marcava, na memória de quem lia a obra, que "tinha alguma coisa no amor deles que não devia acontecer. Mas aconteceu".

$\mathrm{Na}$ origem, o pecado. $\mathrm{Na}$ escolha do palavreado cortante, entretanto simples e possível, cotidiano, a sublimação.

Agreste - ou Malva-rosa, seu contraditório e eclipsado subtítulo - era, desde sempre, uma dramaturgia ambígua e incorreta. Fronteiriça, não aceitava mostrar-se conforme as regras da convenção. Surgia, desde a leitura, como um problema para o palco: que ator - ou projeto de interpretação - seria esse capaz de levar adiante sua poesia árida, sem macular a narrativa com artificialismos desnecessários?

$O$ texto exigiria uma linguagem cênica específica: qual seria ela?

Agreste assustava os sentidos com sua potência poética e com sua capacidade de alimentar imagens deslocadas (Barthes, 1978) - verdadeiras trapaças, invençōes: um furo na cerca, que crescia conforme o compasso do amor; ou um sorriso desdentado perfeito, "de uma fileira só”; ou ainda uma corrida incansável, sertão adentro, como a contrariar a busca do mar glauberiano de Deus e o diabo na terra do sol.

Tudo isso em espaço de palco nu, eroticamente aberto à intervenção do intérprete que,

Quando, em 2004, fui curador da Mostra Santo André do Teatro Contemporâneo, cujo foco era Com(Unidade) - Teatro livre e cenas de identidade, convidei a Cia. Razões Inversas para que mostrasse o espetáculo Agreste no Teatro Conchita de Moraes, agora sob direção de Marcio Aurélio - além de trechos de mais um texto inédito de Newton Moreno, Assombraçôes do Recife velho, com o grupo Os Fofos Encenam, na Casa da Palavra.

Nesta caminhada, pude conhecer de perto a perplexidade dos espectadores e dos artistas-aprendizes da ELT diante do fenômeno que foi a passagem de Agreste, do plano da narrativa até a sua emancipação, como escritura espetacular. E, novamente, com seus novos textos, o contato do ouvido com a palavra pura de um texto inédito do autor.

2 O texto A cicatriz é a flor cumpriu temporada em sessão maldita no Teatro de Arena Eugênio Kusnet, em São Paulo, sob direção de Georgette Fadel. 
elevado à condição de compositor (de uma dramaturgia do corpo?), deveria ser dançarino, e fazer pintura com seu movimento - mas, principalmente, ser o sujeito que, em cada detalhe, pudesse extrair e exalar conceito.

Conceitual, esse era o problema para o sacerdócio do ator: sobrepostas, as imagens narradas pulavam para fora da palavra, como numa dança de véus. Revelavam e escondiam o erótico choque de intimidades - entre personagens, primeiramente, mas também entre leitor e texto, é preciso repetir - sugerido pela meta-narrativa, quase a propor um fetichismo para o olhar pictórico que seria cobrado do espectador.

Pois, no palco, nada se concretizava como realidade dramática (Szondi, 1987). Tudo vingava como pintura imaginária: sugestão, lirismo e narração - ou, de volta, inquieta poesia dramática.

Nunca drama. Em Agreste, até mesmo os diálogos, insistia a rubrica, poderiam surgir como desabrochar da flor, nas expressões do narrador central - um contador de histórias ou dos atores-dançarinos, responsáveis pelo deslocamento da cena para a fronteira com a fisicalidade, com a oralidade e com a construção performática, plástica.

Era exigência no texto ainda não encenado que o espectador imaginasse um mundo desconhecido, puramente ficcional. Este mundo, quase secreto, primordial, podia apenas ser entrevisto pelas frestas do discurso originado na boca da única testemunha a que se tinha acesso concreto no palco - o narrador, representante do dramaturgo dentro da cena.

Este espaço-tempo abstrato - interno, múltiplo e fragmentário como a memória; pura invenção ou documento de identidade para quem narra; mito; deslocamento poético em que a "cultura era o sol", em que "a família era o sol" - nunca se mostrava imediato, pois enlaçava compromisso com o componente épico, para que somente ele realizasse a sua mediação até a realidade cênica.

Metalinguagem obsessiva, não se contentava com uma imaginação qualquer. Pedia ao leitor que penetrasse, deflorasse e constituísse, à sua maneira, a própria criação. Participante, esse espectador ideal de Agreste seria um cocriador, necessário para dar suporte à abertura de possibilidades, típica de uma dramaturgia contemporânea.

Nesta atividade lúdica, em que o sujeito deveria ser chamado sensualmente pela obra de volta a uma espécie de paraíso perdido para reconstruir a trajetória de Adão e de Eva, é que está a grande armadilha forjada por Newton Moreno. Porque o dramaturgo dá corda à identificação e permite, pela participação ativa na criação de imagens apenas sugeridas pelo processo narrativo, que o leitor interfira com o seu próprio erotismo na recuperação do pecado original que mancha com culpa o mundo primevo das criaturas do texto.

Entretanto, quando se mordem as maçãs vermelhas, que são as palavras compostas pelo dramaturgo, ele - de volta à condição de criador, ou como o Deus cristão que manda à Terra o seu representante (ou filho; o narrador?) - revela-se. Então impõe, a todos, que convivam com os elementos que justificam a sua criação. Diz quais são os seus pontos inegociáveis. Evidencia o irredutível de sua presença.

Que o espectador participe, mas que acate as condições do jogo. A serpente dá o "bote/ arataca”.

Com as iscas certeiras, as suas figuras centrais - Etevaldo e Maria, que, como propõe Roland Barthes (1987, p. 24): 1. não chegam a ser personagens, mas figuras cênicas, porque são emanaçôes de uma matriz única: o autor/narrador; 2. que não possuem autonomia fora da narrativa; e 3. que não possuem dramática substantiva (Rosenfeld, 1985) -, a dramaturgia aprisionava e fazia aceitar, a todo custo, uma grande reviravolta: a peripécia do casal lésbico, contada mil vezes pela fala popular em histórias semelhantes às do Recife velho, ou da mitologia do sertão.

Ao olhar, a dramaturgia se insinuava como um poema feito em prosa, dramatizado pelo cordel, pela língua nordestina do sertanejo. 
Mas, escorregadia, ela era também música, que vibrava com forte impacto, nascida dos sons do palavreado requintado e da melodia seca) e que ecoava na cadência de uma mesma rubrica aquela que, precisamente, de tempos em tempos, pedia: tempo!

O tempo marcava o ritmo e a palavra explodia em música. O tempo marcava o ritmo e o gesto se desdobrava em dança. $\mathrm{O}$ tempo marcava o ritmo e a narrativa se construía em camadas sucessivas, fazendo ver que o épico se abria em diferentes níveis de composição.

Opção contemporânea para uma cena pós-dramática, Agreste veio ao mundo como dramaturgia aberta à restauração de estímulos épicos perdidos, com vocação para aquilo que Luis Alberto de Abreu nomeou - inspirado por Mikhail Bakhtin e Walter Benjamin - como busca de um imaginário comum (Abreu, 2003).

No caso de Agreste, esse imaginário comum era, sem dúvida, o de matriz nordestina árida, dolorosamente ressecada pela experiência histórica, ancestral para o autor de Pernambuco.

Mas, ambiguamente, o comum de seu imaginário também era aquele - fértil, regado nos jardins de sua formação teatral (ligada ao conceito de grupo, na Unicamp), em trabalhos com mestres do porte de João das Neves, Marcio Aurelio, Verônica Fabrini, para citar somente alguns - capaz de reunir artistas em processos comunitários, dotados de dinâmicas colaborativas e coletivas. Ou seja, preocupado ainda que no trabalho textual - com a escritura espetacular.

Por isso a escritura, embora aparentemente simples - trata-se apenas de uma narrativa, poderiam acusar -, pula o trampolim da poesia e torna-se material cênico aberto, chama para si a intervenção de outros artistas. Por isso a dramaturgia de Newton Moreno freqüenta os cantos não-mapeados das formas e categorias teatrais, aqueles espaços sagrados em que se escondem dramaturgias body art, como são A cicatriz é a flor (2002) ou Dentro (2002). Por isso seu texto deseja, com libido neotropicalista e múltipla, deslocar-se para aquela zona transitiva, em que moram as perpétuas transformaçôes dos seres não-terminados, onde brincam as criaturas inadequadas e feitas de devir: o paraíso original da arte.

Destas primeiras contradições entre aparência e tecido profundo da obra, surgem outras, que desafiam o olhar crítico: (1) a aposta radical no plano narrativo - nem diálogos há; e uma estranha narração domina toda a primeira parte do jogo cênico, como a insistir que o público aceite as imagens, inclusive aquelas incomuns, que virão depois, na finalização homoerótica - e (2) a linguagem sugestiva, feita com o cinismo de uma única rubrica, para que a encenação traga a cena à fronteira do teatro, para que os atores possam pintar no palco imagens corporais e cênicas, além de dançar um jogo abstrato, proposto pela narração.

Enfim, o texto coloca-se como uma criptografia que deseja ser desvendada pelos artistas da prática do palco.

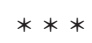

$\mathrm{Na}$ primeira versão que foi a público, na mise-en-space elaborada para o projeto Devassos na dramaturgia ${ }^{3}$, essa massa poética que é Agreste já indicava o seu caráter "desejante”, pois exi-

3 Esse projeto, inspirado pela obra Devassos no paraíso, de João Silvério Trevisan, foi concretizado pela primeira vez em 2002, no Festival de Teatro de Curitiba. Repetiu-se, sempre produzido por Eloísa Elena e sob curadoria de Newton Moreno e Antônio Rogério Toscano, na cidade de São Paulo, nos dois anos seguintes, como parte da programação da Parada do Orgulho GLBT. Estes encontros foram realizados, respectivamente, nas dependências do TUSP (Teatro da Universidade de São Paulo) e no Teatro X, na Praça Roosevelt. Trata-se de um ciclo de leituras de textos teatrais inéditos que proponham reflexões focadas no debate contemporâneo sobre os gêneros sexuais e suas diversas variações. 
gia do espectador (que até ali era somente um ouvinte do grupo Os Fofos Encenam) uma atividade de construção e de colaboração para o que viria a ser sua teatralidade concreta, ainda escondida atrás do radicalismo épico do texto.

O encenador Marcio Aurelio, que há mais de uma década experimenta e transita com muita liberdade por territórios abertos à narratividade com a Cia. Razões Inversas, encontrou neste princípio desejante de Agreste a chave para a emancipação (Dort, 1988) da textualidade: foi em busca de um vigor que a cena só poderia assumir quando se tornasse uma escritura cênica autônoma.

Assim, o que no material textual (e a noção de texto-material é determinante para compreender a dramaturgia contemporânea como processual, liberta de seus tradicionais vínculos textocêntricos) se apontava como um "exercício de narrativa" para a formulação experimental de partituras físicas, como fusão das "duas linguagens" - a oralidade e a dança-teatro; verbo e movimento (rubrica inicial do texto) amplifica-se com o mergulho na polifonia dos recursos multimidiáticos utilizados na cena pelos atores Joca Andreazza e Paulo Marcelo.

Tanto assim, que um espectador que desconhecesse a natureza original do texto provavelmente perderia a noção exata dos formatos estruturais da obra escrita quando assistisse ao espetáculo ${ }^{4}$.
Isso não quer dizer que a cena do espetáculo Agreste suplante ou contradiga a sua textualidade matricial. Pelo contrário, o que se afirma aqui é a natureza desejante da dramaturgia contemporânea, que justamente quer, com suas lacunas formais, chamar para junto de si parcerias artísticas que potencializem seu campo aberto de possibilidades poéticas.

Newton Moreno montou a trajetória de sua narrativa amarrada a um contador de histórias: segundo sua indicação, ele poderia colocar-se solitário e mimético na cena, com a única condição de que fosse um bom condutor; e também que fosse um respeitoso guia, orientado pelas sonoridades absorvidas das fendas poéticas da fábula. Sua marcação sonora: uma sanfona.

Mas o grau de abertura proposto ao encenador é tamanho que o autor explicita que a forma convencional e mimética - ou realista, com um contador de histórias e uma fogueira é somente uma pista, um trampolim, uma dentre todas as demais possibilidades vertiginosas sugeridas por sua cena desejante:
"O narrador pode fazer as vozes de todas as outras personagens, até mesmo do casal, e ainda representar o padre, o delegado, ou as vozes dos moradores, entrando na cena para contracenar com a atriz e depois voltar ao seu posto de narrador".

Apoiados na temática gay dos textos apresentados, os debates investiam nas questôes ligadas à queer culture e às conseqüências éticas e poéticas de se construir cenas focadas tematicamente. Havia quem defendesse que a cena gay era capaz de instituir uma pesquisa formal específica, com identidade própria: tradicionalmente elaborada a partir de sua perspectiva marginal, recheada de elementos grotescos, resultantes das tensões vivenciadas pelo artista gay. Por outro lado, havia quem defendesse que pensar em um teatro gay consistia em fazer um recorte meramente temático; estes, em sua argumentação, evidenciavam os riscos de estigmatização decorrentes desta distinção antropológica para a arte. Participaram do projeto Devassos na dramaturgia, como autores de obras inéditas, os criadores Alberto Guzik, Antônio Rogério Toscano, Fernando Bonassi, João Silvério Trevisan, Luque Daltrozo, Mário Vianna, Newton Moreno, Sérgio Pires, Sérgio Roveri e Vange Leonel.

$4 \mathrm{Na}$ Escola Livre de Teatro, esse relato foi repetidamente colocado, nas discussões acerca do processo de criação deste espetáculo - uma vez que os aprendizes-artistas tinham ali um primeiro olhar voltado para a dramaturgia e um outro, posterior, atento à cena do espetáculo Agreste. 
É bem verdade que a pura indicação em rubrica não garantiria à dramaturgia esse teor de sofisticação que se aponta aqui. E há muitos casos de releituras de textos por parte de encenadores talentosos. Mas releitura não é o caso que se aplica a Agreste.

Como dramaturgia contemporânea aberta, é mais coerente falar mesmo em máquina de sentidos (Deleuze, 2000), ou em dramaturgia desejante. Coisa, aliás, que deve ser considerada como um pilar para que fosse firmada a feliz parceria entre o trabalho (de formalização e escrita) do texto e sua relação (generosa e aberta) com os esforços subseqüentes, de ensaios e de construção da encenação, pela Cia. Razões Inversas.

$\mathrm{O}$ que se pretende dizer aqui, finalmente, é que Newton Moreno aceita e remodela, à sua maneira, a compreensão mais contemporânea do trabalho do dramaturgo. Essa profissão, antes mitificada como a de literatos de gabinete, transformou-se em nosso tempo em uma das partes ativas do processo de construção do espetáculo. Apenas uma.

Longe de perder espaço, o dramaturgo tornou-se agora uma figura em trânsito (Abreu, 2003), não cristalizada. Viva, sua participação no contexto criativo é muito mais vibrante, ao respirar dos mesmos ares que incomodam as crises do processo. Mesmo quando escreve um texto em sua solidão, o novo dramaturgo (que pode ser também - e simultaneamente - um dramaturg, ou um dramaturgista - ou coordenador de roteiros, orientador de mapas etc) trabalha para abrir-se à intervenção do encenador - ou do ator, ou ainda de outro artista capaz de gerar fluxos e estímulos para os caminhos inusitados da criação.

Portanto, é preciso avisar quanto ao risco mais banal: uma leitura conservadora do Agreste pode, sem dúvida, reduzir sua potencialidade cênica e afrouxar sua faceta desejante. Mais do que tudo, corre-se o risco de impossibilitar que se veja com clareza o sentido orgânico existente no trânsito de Newton Moreno entre a palavra e o palco.

Por outro lado, bastante mais confortável: a perspectiva aberta do texto comprova-se quando se assiste ao espetáculo que essa dramaturgia gera - especialmente se confrontada, em uma relação de horizontalidade, com os demais agentes da escritura espetacular, como foi o caso da montagem da Cia. Razôes Inversas. Vê-se, no palco, que Agreste é obra transitiva e generosa, feita para o diálogo criador.

Em 2004, Newton Moreno participou de um processo colaborativo ${ }^{5}$ para a realização do espetáculo Santa Luzia passou por aqui com seu cavalinho comendo capim, no Teatro Popular do SESI, em que se lê no programa:

\footnotetext{
"Construir a dramaturgia de um espetáculo, hoje, impõe a escolha de caminhos, trajetórias. É um permanente cavoucar, na tentativa de abrir canais para fluxos de saída e de entrada do material expressivo que deve ser extraído de nossas galáxias interiores e das representações que encontramos no mundo, fora de nós; são estas, aliás, as que chegam para nos modificar e para dar novo sentido ao que é ser artista.
}

5 Diferentemente de Agreste, que foi escrito e somente depois encenado, em Santa Luzia... Newton Moreno partilhou, comigo (mais uma vez é preciso aqui me revelar, já que escrevi, também, a quatro mãos, este manifesto) e com os atores-criadores, o trabalho de dramaturgia, sob direção de Georgette Fadel. Neste processo houve ainda a participação de uma série de outros artistas, em suas respectivas áreas, todos criadores que interferiram diretamente na definição do material textual e, mais amplamente, na escritura cênica do espetáculo final: Alessandra Domingues (iluminação), Claudia Schapira (figurinos), Emerson Mostacco (produção executiva), Julio Docjsar (criação cenográfica); Lincoln Antônio (direção musical), Luaa Gabanini (assistência de direção), Lu Favoretto (criação coreográfica), Marcelo Romagnoli (assistência de direção) e Tica Lemos (preparação corporal). 
Em linhagem pedagógica que assimila o risco da transformação, o trabalho do dramaturgo inscreve-se em campo plástico, sonoro, rítmico: pois é um desenhar, com diversos instrumentos, grandes mapas abstratos, espetaculares... Polifônicos. Que são abandonados conforme a viagem transcorre e novos horizontes precisam ser explorados.

O texto teatral, agora múltiplo, transforma-se em uma espécie de guia, em uma das forças ativas que permitem que os vários criadores - atores, encenadores, músicos, dançarinos, figurinistas, iluminadores etc - entrem em contato com outros intérpretes da obra de arte: os espectadores.

De fato, em algumas ocasiōes, a dramaturgia pode se tornar um trabalho que exige mais apuro dos ouvidos do que das mãos, mais dos olhos do que da razão ranzinza, acostumada a velhos padrões aprendidos nos cânones. Mais do diálogo do que da emissão. Mais ainda da integração entre a cabeça e o coração.

Abandonada a antiga premissa textocêntrica em que a dramaturgia é palavra de gabinete, é canal unilateral produzida em território de posses demarcadas ou, na mais amarga das confusões, num feudo literário em que o autor é o dono e o senhor, abrem-se perspectivas para que a criação espetacular vigore da colaboração criativa de muitas fontes.

Neste estágio avançado, somente a confiança nas parcerias pode auxiliar para o amadurecimento de uma idéia. Além do encenador, o ator-criador, neste contexto, emerge como figura fundamental. Ele é o nascedouro daquilo que pode ser erro, mas também daquilo que se enraíza como um depoimento poético vivo.

Afinal, o ator é o sacerdote do rito, quem se compromete com as palavras ditas no missal sagrado que se desdobra no espaço cênico. Neste nosso trabalho, em que aguardamos para que Santa Luzia venha dar uma espiada, o processo colaborativo esteve focado no material gerado pelos atores.
Deles partiram as concepções iniciais das cenas, neles explodiram as crises. Mas como o fluxo não pode ser interrompido, toda a expressão migrou, em vai-e-vem, para os outros pólos da criação. Por isso, para toda a equipe, esse processo assume a sua postura de formação, com radicalismo. Os aprendizados, na cegueira dos dias, esclarecem muito mais do que idéias brilhantes, mas solitárias, que não iluminam olhos alheios."

Esse pequeno manifesto dá a idéia exata de alguns dos princípios, agora assumidos, do que se pretende enquanto se escreve uma dramaturgia contemporânea. Embora diga respeito a um espetáculo posterior, apontam-se nele questôes que já freqüentavam o corpo transitivo e desejante da dramaturgia de Agreste.

Se não fosse por essa perspectiva alargada, talvez Marcio Aurelio pudesse ter hesitado diante da hipótese, comprovadamente eloqüente, de utilizar múltiplos recursos poéticos - polifonia, microfones, distanciamento, narrativas sobrepostas, fragmentação, descontinuidade, projeção de slides, metonímias gestuais etc. - para dar vazão à sua pesquisa de linguagem própria como encenador.

Marcio Aurelio encontrou em Newton Moreno um vetor poderoso de continuidade para sua pesquisa que atravessa décadas. $\mathrm{O}$ tom regionalista da fala e as "incelenças" a serem cantadas no enterro sertanejo foram peneirados pelo formalismo extremado do jogo dos atores. Texturas cênicas foram criadas com linhas e pesos, evidenciaram os aspectos cruéis da narrativa e uma outra escritura, grafada no espaço e no tempo, nos sons e nas luzes, desdobrou-se do desejo original da fábula homoerótica de Newton Moreno.

Texto-material, esboço: o desejo está no centro gravitacional da dramaturgia do autor. E não só o desejo, o homoerotismo é tema recorrente na sua dramaturgia, desde a estréia, com Deus sabia de tudo e não fez nada (2000), em que as matrizes de sua ironia fina (presentes também em Agreste) associavam-se a um discur- 
so de protesto por isonomia e por visibilidade dos desejos.

Já em seu primeiro texto, o autor dava voz ao gay pride - que tem atraído, desde os anos 90, multidões aos manifestos festivos pelas ruas de São Paulo. As superposiçōes narrativas, de fala poética aguda, antecipavam os recursos formais e o tema do massacre incendiário da esposa deste drag king do sertão nordestino que é o Etevaldo de Agreste.

Em mais esse aspecto desejante, Newton Moreno extrapola a pesquisa formal. Mergulha em sua necessidade pessoal de refletir sobre a questão do homoerotismo, tema de sua dissertação de mestrado, orientada por Sílvia Fernandes e defendida na ECA/USP em 2003, intitulada A máscara alegre - Contribuiçôes da cena gay para o teatro paulista.
Mesmo Dentro, peça de tema radical que abre a cena para a prática do fisting, indica esse caráter pouco corriqueiro de sua escritura teatral, que insiste em relativizar, com seu jogo de palavras e idéias, os conceitos ligados ao teatro marginal. Em sua batalha por um novo olhar sobre a diferença, o autor lança os dados para que se consagre no palco a transgressão poética, com o que é incomum e vive à margem.

Formalmente desejante e inspirada pelo homoerotismo, a dramaturgia de Newton Moreno - nesses seus primeiros passos - tem recolocado em pauta no teatro brasileiro, sob a condição de militante, tanto uma nova abordagem para a função do dramaturgo, como também a batalha por direitos humanos, avançando de modo mordaz contra a discriminação por orientação sexual.

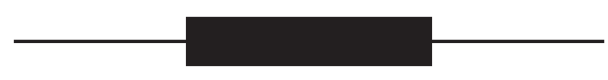

\section{Referências bibliográficas}

ABREU, Luis Alberto de. A restauração da narrativa. In: O sarrafo, 2003.

- Processo colaborativo - relato e reflexões sobre uma experiência de criação. In: Cadernos da ELT. Ano 1, n. 0. Santo André: ELT, 2003.

BARTHES, Roland. Aula. São Paulo: Cultrix, 1978.

Racine. L\&PM, 1987.

BROOK, Peter. O teatro e seu espaço. São Paulo: Vozes, 1970

DELEUZE, Gilles \& GUATARI, Felix. O anti-Édipo. Lisboa: Assírio \& Alvim, 2000.

DORT, Bernard. La représentation émancipée. Paris: Actes Sud, 1988.

ROSENFELD, Anatol. O teatro épico. São Paulo: Perspectiva, 1985.

SZONDI, Peter. Theory of modern drama. Londres: Polity Press, 1987. 